\title{
Male phenotype predicts extra-pair paternity in pied flycatchers
}

\author{
David Canal $^{1,3)}$, Jaime Potti ${ }^{1)}$ \& José A. Dávila ${ }^{2)}$ \\ $\left({ }^{1}\right.$ Estación Biológica de Doñana — CSIC, Department of Evolutionary Ecology, Av. \\ Américo Vespucio s/n, 41092 Sevilla, Spain; ${ }^{2}$ Instituto de Investigación en Recursos \\ Cinegéticos, IREC (CSIC-UCLM-JCCM), Ronda de Toledo s/n, 13005 Ciudad Real, Spain)
}

\section{Summary}

Extra-pair paternity has the potential to increase male reproductive success and in turn the potential for sexual selection to act on male traits predicting extra pair mate success. There is large variation among European populations of pied flycatchers (Ficedula hypoleuca) in the extent to which male traits predict success in extra pair mating behaviour. In an Iberian population with a relatively high proportion of extra-pair young multiple male traits were involved in extra pair paternity success. Cuckolder males had larger tarsi and more attractive sex ornaments (blacker dorsal plumage and larger forehead patches) than the individuals they cuckolded, results not replicated in other populations. Previous studies in the species have shown that all traits associated with achieving success in extra pair paternity in our population are heritable and likely reliable indicators of male quality. Siring additional young was an advantageous strategy for males as it did not imply loss of paternity in their own nests. Our results, thus, suggest that this behaviour may enhance the evolution of male traits associated to success in extra-pair paternity in this population.

Keywords: Extra-pair paternity, male phenotype, pied flycatcher, sexual selection.

\section{Introduction}

A large body of work has conclusively demonstrated in many vertebrates that social monogamy does not necessarily imply genetic monogamy (fish, Sefc et al., 2008; amphibians, Liebgold et al., 2006; mammals, Cohas \&

3) Corresponding author’s e-mail address: davidcanal@ebd.csic.es 
Allainé, 2009; birds, Griffith et al., 2002). Although the reasons for female promiscuity are not obvious and are consequently much discussed (Dixon et al., 1994; Jennions \& Petrie, 2000; Arnqvist \& Kirkpatrick, 2005; Simmons, 2005; Akçay \& Roughgarden, 2007; Griffith, 2007; Mays et al., 2008), siring additional offspring outside the pair bond (extra-pair young; EPY) seems clearly adaptive for males by increasing their reproductive success while often taking advantage of the paternal care provided by other males (extrapair paternity; EPP). Independent of its adaptive function, EPP may play an important role in the evolution of sexual characters when its distribution among males is non-random and heritable male traits predict EPP success (Webster et al., 1995). As long as EPP is not counterbalanced by paternity losses at the within pair level (Andersson, 1994; Webster et al., 1995), EPP will increase the variance of male fitness and, in turn, the strength of sexual selection on traits predicting paternity success.

A number of studies have related either success in EPP or loss of paternity to male age (Bouwman et al., 2007; Lubjuhn et al., 2007), ornamentation (Bittton et al., 2007; Balenger et al., 2009), condition (Møller et al., 2003) or body size (Yezerinac \& Weatherhead, 1997; Hutchinson \& Griffith, 2008) though even in different populations of the same species conflicting results regarding which traits are important for females are commonly reported (Akçay \& Roughgarden, 2007). Different environmental conditions and specific female preferences may cause targets of sexual selection to diverge across populations (Endler, 1977; Lande, 1981; Schluter \& Price, 1993; Dale et al., 1999). Additionally, loss of trait variability caused by prolonged selection may cause differences in what traits are currently better signalling male quality across populations (Dale et al., 1999) and thereby in the criteria used by females in partner choice (Endler \& Houde, 1995; Freeberg et al., 1999). Given the consequences EPP may have on the evolution of male traits, understanding the role of the male phenotype in this widespread phenomenon and measuring its impact on individual reproductive success are central tasks (Westneat \& Stewart, 2003; Albrecht et al., 2009).

The pied flycatcher (Ficedula hypoleuca) is a predominantly monogamous, hole nesting songbird. After mating, a number of males try to acquire a second female and some succeed in becoming socially polygamous (reviewed in Lundberg \& Alatalo, 1992). In addition to male age, sex traits such as mantle colour, wing and forehead patch sizes have been shown to function as quality indicators in pied flycatcher males and/or being sexually 
selected in social contexts in the species (Potti \& Montalvo, 1991b; Lundberg \& Alatalo, 1992; Slagsvold \& Lifjeld, 1992; Sætre et al., 1994; Lehtonen et al., 2009a) or in the closely related collared flycatcher Ficedula albicollis (Gustafsson et al., 1995; Ellegren et al., 1996; Sheldon et al., 1997; Pärt \& Qvarnström, 1997; Török et al., 2003). Previous studies have also highlighted genetic polygamy in the pied flycatcher (e.g., Lifjeld et al., 1991; Gelter \& Tegelström, 1992; Rätti et al., 1995, 2001; Brün et al., 1996). However, the evidence of EPP in relation to male traits is ambiguous, with some work associating variation in paternity to male secondary sex traits (Lifjeld et al., 1997; Lehtonen et al., 2009a) and others failing to show such relationships (Rätti et al., 1995; Moreno et al., 2010). Several studies have shown both genetic and phenotypic differences (e.g., variation in plumage colour) between Iberian and northern European populations (e.g., Lundberg \& Alatalo, 1992; Haavie et al., 2000; Lehtonen et al., 2009b; Qvarnström et al., 2010). In the only study performed to date in Iberian pied flycatchers paternity loss within the own nest was unrelated to ornamentation but was associated to male age and corticosterone levels, whereas traits associated to EPP success were not analyzed (Moreno et al., 2010). Therefore, whether male phenotype (age, size and ornaments) affects EPP success and how the latter influences male reproductive fitness and thereby sexual selection on male secondary traits are questions largely unresolved in these populations.

The aims of our study were (1) to examine whether male phenotype (age, size and ornaments) predicts extra-pair mating; and (2) to assess the impact of this behaviour on male reproductive success in a Spanish population of pied flycatchers. To this end, we used molecular tools to find EPY and the males who sired them. We then focus on which male traits are related to EPP and quantify how this behaviour affects male reproductive success.

\section{Material and methods}

\subsection{Field work}

The study was done during the 2005 breeding season in a population of pied flycatchers breeding in nest-boxes in central Spain which has been monitored since 1984 (e.g., Potti et al., 2007; Potti \& Canal, 2011).

All nests were regularly checked to ascertain exact laying date, clutch size, hatching date and number of fledglings. Parent birds were captured with 
a nestbox trap while they were feeding 8-day-old nestlings. All adult birds were marked with a numbered metal ring and a unique combination of colour rings. Age of many breeding birds was known with precision due to high natal philopatry (Potti \& Montalvo, 1991a). Previously unringed birds were aged as first year (yearlings hereafter) or older on the basis of plumage traits (Potti \& Montalvo, 1991b; Lundberg \& Alatalo, 1992; Svensson, 1992). Birds were weighed (to the nearest $0.1 \mathrm{~g}$ ) and measured for tarsus length (to the nearest $0.01 \mathrm{~mm}$ ), wing length (to the nearest $0.5 \mathrm{~mm}$ ) and height and width of the forehead patch (to the nearest $0.01 \mathrm{~mm}$ ). The primary feather where the white wing patch starts (counted descendently and looking at the outer feather vane) was also recorded to give an estimate of the (unrecorded in the study year) wing patch area (as the former predicts the latter: $R^{2}=$ $54 \%$; authors' unpubl. data). The area of the forehead patch was calculated as patch height $\times$ width. In males, the percentage of black feathers in the back of mantle was visually estimated, high values indicating a black plumage (Potti \& Montalvo, 1991c; Lundberg \& Alatalo, 1992).

Nestlings were ringed, measured and weighed at the age of 13 days. Blood samples were taken from all individuals by puncturing the brachial vein and stored in ethanol.

\subsection{Molecular methods}

Individuals were genotyped at seven polymorphic microsatellite loci (Table 1). Four of these loci had been developed by Ellegren (1992) (fhu1 and fhu2) and Primmer et al., (1996) (fhu3 and fhu4) and the rest were developed by us (Canal et al., 2009). To further increase reliability in the assignment of genetic fathers we genotyped all individuals from nests containing young having mismatches with their putative father (see below) with three additional primers (fhy444, fhy466 and fhy310; Leder et al., 2008). PCR conditions followed the authors' recommendations.

Microsatellite markers were ran on an ABI PRISM 3130xl DNA sequencer (Applied Biosystems). Allele sizes were determined according to Genescan 500-LIZ size standard and Genemapper version 4.0 (Applied Biosystems). Our sample size was 121 nests containing 578 nestlings. Once genotyped, 8 nests were excluded from further analyses since it was impossible to determine either presence or absence of EPP in them. All these nests shared similar features: small brood size (2-3 nestlings) and unknown (i.e., 
Table 1. Numbers of alleles $(N)$ at microsatellites, polymorphic information content (PIC), observed and expected heterozygosities ( $H_{\text {obs. }}$ and $H_{\text {exp. }}$, respectively) and probability of exclusion $\left(P_{\text {excl. }}\right)$ in the pied flycatcher study population.

\begin{tabular}{lrlccc}
\hline Locus & $N$ & $H_{\text {obs. }}$ & $H_{\text {exp. }}$ & PIC & $P_{\text {excl. }}$ \\
\hline Fhu1 & 3 & 0.534 & 0.607 & 0.523 & 0.686 \\
Fhu2 & 7 & 0.711 & 0.704 & 0.651 & 0.548 \\
Fhu3 & 7 & 0.472 & 0.556 & 0.530 & 0.643 \\
Fhu4 & 21 & 0.863 & 0.891 & 0.880 & 0.217 \\
Fhy6-126 & 42 & 0.956 & 0.958 & 0.955 & 0.087 \\
Fhy1-25 & 7 & 0.758 & 0.731 & 0.692 & 0.491 \\
Fhy3-60 & 21 & 0.944 & 0.927 & 0.922 & 0.148 \\
Fhy310 & 13 & 0.873 & 0.872 & 0.858 & 0.259 \\
Fhy444 & 16 & 0.888 & 0.878 & 0.865 & 0.248 \\
Fhy466 & 12 & 0.849 & 0.832 & 0.811 & 0.331 \\
\hline
\end{tabular}

The combined probability of exclusion for all loci was $>99.9 \%$.

unidentified) social father. In the remaining 113 nests, 5\% of the nestlings (out of 560) were unsampled due to predation or mortality prior to sampling. Thus, final sample size was 743 individuals: 531 chicks and 212 adults (113 females and 99 males, 14 being polygynous). We also captured four males defending natural holes in trees but they did not sire any young within the nestbox population and, thus, were not further considered.

\subsection{Paternity analysis}

The parentage analysis was performed using the program CERVUS 2.0 (Marshall et al., 1998). The combined probability of exclusion for all loci, given that the mother's alleles are known, was $>99.9 \%$ (Table 1). This is the probability averaged over all loci that a randomly chosen male in the population will not match the alleles found in offspring. Using a maximum likelihood method, CERVUS calculates the confidence of paternity through a simulation where allele frequencies, number of candidate parents (103, in our case), proportion of candidate fathers sampled from the population (0.8), percentage of loci typed (0.98) and sampling errors (0.01) are taken into account. The simulation estimates the delta values, i.e., the difference in LOD (natural logarithm of the likelihood ratio) scores between the first and second most likely father at a given confidence level in order to generate a list of the most likely sires for a given nestling. We based our paternity assign- 
ments on a 95\% confidence level. After null alleles were taken into account (as both Fhu1 and Fhu3 loci showed significant heterozygote deficits relative to Hardy-Weinberg equilibrium), genotypes of all young matched with their putative mother, hence no case of intraspecific brood parasitism was confirmed. A nestling was considered as EPY if their social father was not in the list of most likely sires given by CERVUS, or if there was another male in the population with a better match than the putative father (i.e., with positive and higher LOD scores). We identified the extra-pair sire when a male had none or one mismatch (i.e., due to null alleles; it was checked manually) and a high LOD score for a given nestling. Some nestlings were considered EPY of unknown sires (i.e., unidentified in the field) since no candidate male showed good matches with them.

\subsection{Statistical analyses}

To see which male traits are important in EPP contexts we ran two different groups of tests: at the population level and pair wise tests which directly compare cuckolder males with the social males they cuckolded. The determinants of gaining and losing paternity at the population level were explored through three steps. First, we examined the variables involved in paternity loss (by comparing males losing and not losing paternity). Then, we did the same with the variables involved in paternity gain (by comparing males gaining and not gaining paternity). In both cases we used generalized linear models with binomial distribution and logit link functions, wherein dependent variables (gaining/not gaining EPP or losing/not losing EPP) were coded as $0 / 1$ and laying date, male age, size and plumage traits were held as explanatory variables. The link between gaining and losing paternity was examined with a $2 \times 2$ chi square goodness-of-fit test. In all these analyses we used data from both monogamous and primary nests of polygamous males after having previously confirmed the absence of differences in fledgling success between both types of nests $\left(\chi_{1}^{2}=1.53, p=0.21\right)$. Data from secondary broods of polygamous males were not considered in analyses to avoid pseudo-replication and because their status could affect paternity of the offspring if males spend less time potentially guarding them during the fertile period (Lundberg \& Alatalo, 1992). Wing length and the primary feather where the wing patch begins vary with age and were standardized before they were entered into the models. The probability that an EPP event occurred was also modelled as a function of the breeding date and 
the female breeding status of the social nest (monogamous, primary or secondary female) with a generalized linear model (binomial distribution and logit function).

Matched comparisons of traits and breeding dates between the cuckolder male(s) and the social male they cuckolded were done with pair-wise $t$-tests. Due to non normal data distribution, age and plumage colour were analyzed with non-parametric, matched-pairs Wilcoxon tests. As in the models above, wing length and the primary feather where the wing patch begins were standardized by age before analyses. In three nests, young were fathered by two extra-pair males and we used the averages of both males. Data from secondary nests of polygamous males with EPP were not considered in analyses.

The impact of gaining or losing extra pair paternity on male total genetic reproductive success (number of fledged young) was assessed with a general linear model (normal distribution) in which the two potentially independent processes of gaining or losing paternity were treated as two explanatory binary factors (gaining or not, losing or not). As female fecundity is a potential source of variation in reproductive success we also tested whether clutch size was related to male traits and female involvement in EPP with generalized linear models (Poisson distribution, and breeding date as explanatory variable).

All analyses were done in SAS 9.1 (SAS Institute, 2004). In all cases, model selection was carried out by starting from fully saturated models and removing one by one the least significant variables, starting from the highest order interactions. While performing model selection main effects were not removed before their interactions. Throughout the text means are given with $1 \mathrm{SE}$. We also present standardized effect sizes (Cohen's $d$ ) as well as their 95\% confidence intervals (CI) calculated with the 'effect size calculator' by David B. Wilson (available online at http://www.campbellcollaboration.org/resources/effect_size_input.php). In order to not overestimate effect sizes in paired tests $d$ values were computed using means and standard deviations (Dunlop et al., 1996).

\section{Results}

\subsection{Patterns of extra-pair paternity}

$31 \%$ of adults (70/213) engaged in EPP. As a consequence, 20\% (106/533; 95\% confidence limits: $16.5-23.3 \%$ ) of the genotyped offspring, across $39 \%$ 
(45/113) of nests, were fathered by an extra-pair male. After exclusion of secondary females, the population level EPP rates varied slightly, the respective figures being 33\% (65/198) of adults, 19\% (101/517; 95\% confidence limits: $16.1-22.9 \%)$ of genotyped offspring and $40 \%$ (40/99) of nests. The genetic father could be identified for 67\% (71/106) of the EPY.

The probability of finding an EPY in a nest was unrelated to breeding date $\left(\chi_{1}^{2}=0.59, p=0.44, d=0.14, \mathrm{CI}=0.37\right)$ or female breeding status as regards social polygamy $\left(\chi_{1}^{2}=2.00, p=0.37, d=0.26\right.$, $\left.\mathrm{CI}=0.37\right)$.

\subsection{Comparisons at the population level}

None of the male traits analyzed had a significant influence on the probability of losing paternity (Table 2a) or gaining EPP (Table 2b). All except two of the identified males that attained EPP were at least 2 years old (yearling vs. older males: $\chi_{1}^{2}=5.66, p=0.017$ ) and both young cuckolder males were also simultaneously cuckolded (Table 3 ). However, when the influence of breeding date $\left(\chi_{1}^{2}=12.1, p=0.005, d=0.74\right.$, CI $=0.42$ ) was

Table 2. Comparisons between (a) males that lost and those not losing paternity and (b) males that gained and those not gaining paternity in the population at large. Statistics are from a generalized linear model modelling the probability of losing (a) or gaining (b) paternity. Wing length and first primary with patch were standardized by age before introducing them in the models.

Estimate

$\chi_{1}^{2}$

$p$

Cohen's $d$

CI

(a)

Forehead patch area $\left(\mathrm{mm}^{2}\right.$ Plumage blackness (\%)

Tarsus length (mm)

Wing length (mm)

$1^{\text {st }}$ primary with patch

Body weight (g)

$-0.019 \pm 0.015$

1.70

0.191

0.2685

0.41

$0.006 \pm 0.009$

0.53

0.465

0.1498

0.4

$-0.145 \pm 0.390$

0.14

0.709

0.0764

0.4

$-0.094 \pm 0.149$

0.40

0.526

0.1301

0.41

$-0.521 \pm 0.300$

3.21

0.073

0.3824

0.42

$-0.826 \pm 0.543$

2.39

0.122

0.3213

0.41

(b)

\begin{tabular}{lrrrrl} 
Forehead patch area $\left(\mathrm{mm}^{2}\right)$ & $0.022 \pm 0.018$ & 1.60 & 0.203 & 0.2604 & 0.4 \\
Plumage blackness (\%) & $0.001 \pm 0.013$ & 0.58 & 0.446 & 0.1568 & 0.4 \\
Tarsus length $(\mathrm{mm})$ & $0.037 \pm 0.518$ & 0.54 & 0.462 & 0.1504 & 0.4 \\
Wing length (mm) & $0.112 \pm 0.190$ & 0.35 & 0.552 & 0.1216 & 0.4 \\
$1^{\text {st }}$ primary with patch & $-0.401 \pm 0.357$ & 1.30 & 0.253 & 0.2408 & 0.41 \\
Body weight (g) & $-0.117 \pm 0.627$ & 0.04 & 0.851 & 0.0410 & 0.41 \\
\hline
\end{tabular}


Table 3. Number of males gaining, losing paternity or simultaneously gaining and losing in the population in relation to their age.

\begin{tabular}{lccr}
\hline & Yearlings & Adults & Total \\
\hline Males only gaining paternity & 0 & 17 & 17 \\
Males only losing paternity & 9 & 23 & 32 \\
Males gaining and losing & 2 & 6 & 8 \\
Males neither gaining nor losing & 13 & 29 & 42 \\
Total & 24 & 74 & 99 \\
\hline
\end{tabular}

taken into account the differences in age related to EPP success disappeared $\left(\chi_{1}^{2}=0.73, p=0.39, d=0.17\right.$, CI $\left.=0.39\right)$. After comparisons were restricted to older (2-5 years old) males, no differences in the probability of gaining or losing EPP were found among age classes (all comparisons $p>0.12$, results not shown).

Gaining EPP did not influence the probability of simultaneously losing paternity $\left(2 \times 2\right.$ chi square table on the total values in Table $3 ; \chi_{1}^{2}=0.98$, $p=0.32, d=0.2, \mathrm{CI}=0.39$ ). Thus, for identified males, gaining paternity in other nests did not imply simultaneous loss of paternity in their own nests (17 out of 25) and, similarly, loss of paternity within the own nest was not associated to gaining it in other nests (32 out of 40; Table 3). Otherwise, five males engaged in EPP with two different females whereas only three females did so with more than one extra-pair male.

\subsection{Cuckolder males versus males they cuckolded}

Extra-pair males had significantly larger tarsi (19.49 \pm 0.10 vs. $19.17 \pm 0.12$ $\mathrm{mm} ; t=-2.27, p=0.034, d=0.63, \mathrm{CI}=0.57)$, had larger forehead ornaments $\left(60.13 \pm 3.17\right.$ vs. $48.81 \pm 3.88 \mathrm{~mm}^{2} ; t=-2.24, p=0.037$, $d=0.71, \mathrm{CI}=0.65)$ and darker plumages $(92.7 \pm 2.9 \mathrm{vs} .83 .62 \pm 5.1 \%$ of black feathers; $Z=2.07, p=0.038, d=0.55$, CI $=0.54$ ) than the social males they cuckolded (Figure 1). There were no differences between extrapair and cuckolded males in the remainder of measured traits: wing length (age corrected values: $0.19 \pm 0.34$ vs. $-0.06 \pm 0.3 \mathrm{~mm} ; t=0.54, p=0.59$, $d=0.35$, CI $=0.62$ ), white patch's first primary feather (age corrected values: $-0.05 \pm 0.17$ vs. $-0.06 \pm 0.14 ; t=0.03, p=0.97, d=0.1$, $\mathrm{CI}=0.52)$, body weight $(12.60 \pm 0.45$ vs. $12.39 \pm 0.42 \mathrm{~g} ; t=-1.40$, 
(a)

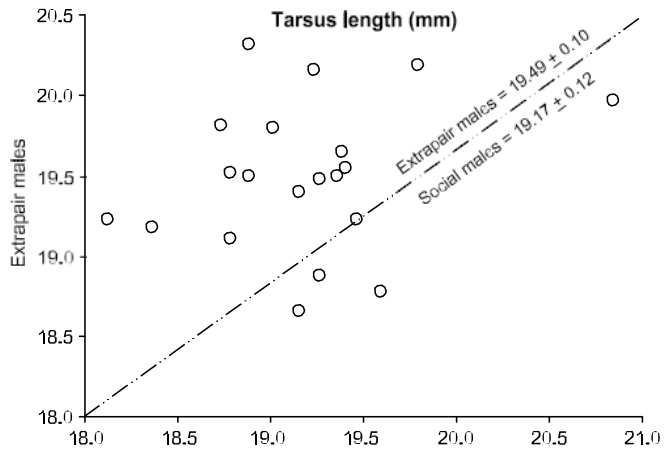

(b)

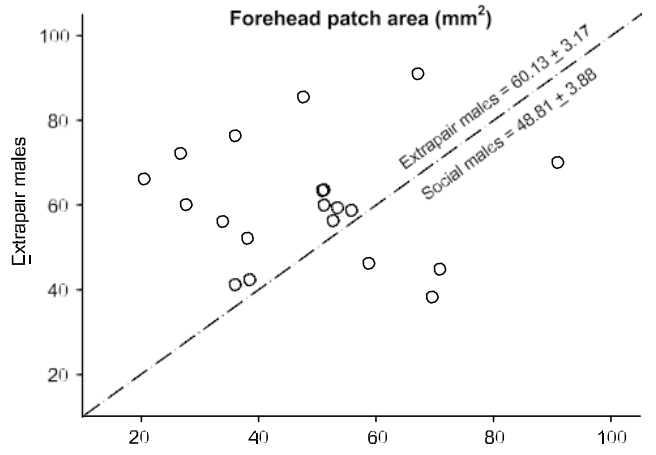

(c)

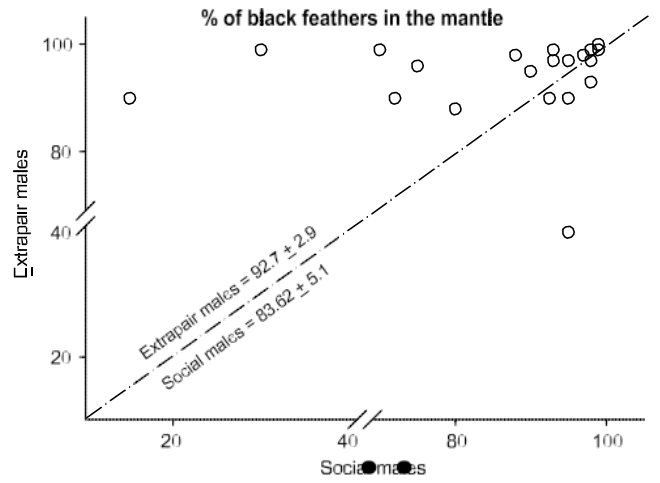

Figure 1. Comparisons of (a) tarsus length, (b) forehead patch size and (c) plumage blackness in cuckolder males and the males they cuckolded. Dots above lines indicate larger values in extra-pair males than in the males they cuckolded in the analysed traits. Average (SE) population values were $19.35 \mathrm{~mm}(0.05), 55.19 \mathrm{~mm}^{2}$ (1.39) and $82.85 \%$ (2.3) for tarsus length, white patch size and plumage blackness, respectively.

$p=0.18, d=0.47, \mathrm{CI}=0.6)$ and age $(2.95 \pm 0.3$ vs. $2.44 \pm 0.24$ years; $Z=0.79, p=0.42, d=0.41, \mathrm{CI}=0.57)$. However, the lack of age-related 
differences in these comparisons should be taken with caution as the identity of the cuckolder was unknown in 6 out of 11 cuckolded yearling males and hence sample sizes were small.

Cuckolder males bred, on average, 3.9 days earlier than the males they cuckolded ( $t=3.06, p=0.004)$. However, none of the traits predicting EPP success was related to male arrival date in earlier work (Potti \& Montalvo, 1991b) or to breeding date in this study (tarsus length: $r=0.037, p=$ 0.7, forehead patch size: $r=-0.024, p=0.8$ and plumage blackness: $r_{\mathrm{s}}=0.049, p=0.62$ ). That is, early males were not the larger or more ornamented individuals, implying that the association found between EPP success and male traits is not a consequence of the breeding date. Further, the three characters were not associated to male age and all were unrelated to each other (results not shown, all $p>0.13$ ).

\subsection{Influence of EPP on male reproductive output}

Gaining as well as losing EPP had independent and significant influences on male reproductive output $\left(\chi_{1}^{2}=30.83, p<0.001, d=1.3\right.$, CI $=0.46$ and $\chi_{1}^{2}=50.51, p<0.001, d=1.96, \mathrm{CI}=0.54$, respectively). The interaction of both processes was marginally non significant $\left(\chi_{1}^{2}=3.44, p=0.057\right.$, $d=0.38$, CI $=0.4$ ) since the reproductive success of males involved in faithful matings was similar to that of cuckolder males simultaneously cuckolded (4.6 \pm 0.2 vs. $3.8 \pm 0.5 ; \chi_{1}^{2}=1.84, p=0.175, d=1.7, \mathrm{CI}=$ 0.38). Between-groups comparisons of male reproductive success showed that cuckolder males fledged more young $(7.4 \pm 0.3)$ than males involved in faithful matings $\left(\chi_{1}^{2}=33.3, p<0.001, d=2.27\right.$, CI $\left.=0.77\right)$ and these, in turn, fledged more young than males exclusively losing paternity $(2.4 \pm 0.2$; $\chi_{1}^{2}=41.01, p<0.001, d=2.22$, CI $=0.68$ ).

Clutch size was unrelated to the measured male traits (all $p>0.43$ ) and there was no difference in clutch size between clutches with and without EPY (5.5 \pm 0.1 and $\left.5.4 \pm 0.1 ; \chi_{1}^{2}=0.12, p=0.72, d=0.06, \mathrm{CI}=0.36\right)$. The proportion of EPY per brood was $0.18( \pm 0.03)$ young on average, there being only 3 EPY 'pure’ broods in the whole population.

\section{Discussion}

We have gathered evidence for the operation of sexual selection in extra-pair mating behaviour for traits signalling male quality in the pied flycatcher. 
Cuckolder males were larger and displayed darker plumages and larger forehead ornaments than the males they cuckolded, results not replicated in the abundant earlier literature on this model species in sexual selection studies. Cuckolder males enjoyed increased reproductive fitness and compensated for the risk of simultaneous cuckoldry since, when this happened, their reproductive success was similar to that of males only involved in faithful matings. This study, thus, presents additional information concerning EPP and the associated possibility of intensified sexual selection in a species for which there is contradictory information in this respect (Rätti et al., 1995; Lifjeld et al., 1997; Dale et al., 1999; Lehtonen et al., 2009a; Moreno et al., 2010). The percentage of extra-pair young in our study (20) was higher than in most pied flycatcher populations studied to date (with reported rates ranging between 4 and 11\%; Lifjeld et al., 1991; Rätti et al., 2001; Lehtonen et al., 2009a; Moreno et al., 2010), except for one Swedish locality (24\%; Gelter \& Tegelström, 1992), which provided us with a relative large number of extra pair males, making our study more powerful as to the chance of detecting an association between male phenotype and EPP success.

As in other studies on EPP in birds (e.g., Yezerinac et al., 1995; Strohbach et al., 1998; Bitton et al., 2007; Kawano et al., 2009; Lehtonen et al., 2009a), we were unable to identify the father of a number of EPY (33\%). Although in some studies this lack of resolution may be due to insufficient sampling by researchers it also may be due to other reasons. In our case, we assume that EPY with unknown fathers were sired either by males breeding outside the study area or by floaters. In general, floaters are thought to be young, low-quality or subordinate individuals, although Kempenaers et al. (2001) showed that floaters may have a significant role in EPP in tree swallows. We concur with Lehtonen et al. (2009a) in the need of more studies to understand the reproductive strategies of floaters in pied flycatchers and other avian species. In addition, although our results suggest a positive role for males with more elaborate traits in achieving EPP, caution should be taken in their interpretation since our effect size estimates had some uncertainty (broad CIs), given the low sample size in pair wise comparisons (not infrequent in behavioural ecology studies; Nakagawa, 2004; Garamszegi, 2006). In addition, our conclusions are drawn from one breeding season but EPP patterns, far from being constant, could undergo yearly variation resulting from interactions among a suite of changing ecological factors (breeding density and synchrony, operational sex ratio and/or weather conditions; Griffith et al., 
2002). As 5\% of nestlings were missed (due to predation or mortality prior to sampling) the estimation of EPP rate at the population level could vary slightly ( $\pm 2 \%$, in case that all missed young were EPY or WPY).

A male's success in EPP was contingent on its phenotype. In particular, as reported in other populations (Lehtonen et al., 2009a; Moreno et al., 2010), age had a decisive influence on the probability of gaining paternity. Among those males successful in siring EPY, all except two were adult but, interestingly, the probability of gaining EPP did not vary with age among older ( $>1$ year) males. Some authors (e.g., Wetton et al., 1995; Bouwman et al., 2007) have suggested that females engaging in EPP should prefer older males as age and, thus, long-term survival, may be considered a quality indicator. In fact, male age is one of the most common factors associated to paternity in (genetically) polyandrous systems across different taxa (for references, see Kokko \& Lindström, 1996; Griffith et al., 2002). However, analyses at the population level showed that breeding early was important to attain EPP for males as the number of fertile females (the necessary resource to attain EPP) may decrease with the advance of the season (Kokko et al., 2006). Hence, the high EPP success found among older males may be confounded by agerelated differences in settlement and breeding phenologies. In most populations of pied flycatchers, including the southern ones, yearling males usually arrive at the breeding areas very late in the season, when most pairs are already established (Potti \& Montalvo, 1991b; Lundberg \& Alatalo, 1992). Thus, it could be argued that if finding a mate late in the season is a hard task for many yearling males, their chance to engage in EPP (if ever paired) will be even lower (Johnson et al., 2002; Canal et al., data not shown). On the other hand, with almost all pair bonds already established females paired to young males should have many candidate males available to engage in episodes leading to EPP. Therefore, as our analyses accounting for breeding date highlight, the importance of male age in achieving EPP is a consequence of the typical yearling males' late phenology.

Whereas tests at the population level did not reveal any difference between cuckolder and cuckolded males, paired comparisons showed that, irrespective of their age and breeding date, extra-pair males were larger and displayed higher quality ornaments than the males they cuckolded. The discrepancies between both types of comparisons may stem from the fact that a male phenotype relative to those of his neighbours is likely to be more important for females than the male's phenotype relative to the population as a whole 
(Webster et al., 2001), given the rather limited female sampling of potential mates in this species (Potti \& Montalvo, 1991b; Dale \& Slagsvold, 1996).

In avian species, male variation in the ability to attain EPP or, alternatively, avoid loss of paternity have been commonly related to size (Weatherhead \& Boag, 1995; Neto et al., 2010) and quality of plumage ornaments (e.g., Kempenaers et al., 1997; Cordero et al., 1999; Bitton et al., 2007). Examples of multiple traits being sexually selected are also frequent, though their role in determining male reproductive success remains unclear (reviewed in Candolin, 2003). From an adaptive point of view (Møller \& Pomiankowski, 1993), multiple traits may signal multiple qualities (Jawor et al., 2004; Van Doorn \& Weissing, 2004;), be redundant signals of the same aspect of quality allowing more accurate individual assessments (Zuk et al., 1992; Candolin \& Voigt, 2001) or not indicate male quality but facilitate detection or signal reception (Pomiankowski \& Iwasa, 1993; Iwasa \& Pomiankowski, 1994). Previous work with European flycatchers indicates that all male traits conferring success in our study have significant heritability in several populations (Alatalo \& Lundberg, 1986; Potti \& Merino, 1994; Qvarnström, 1999; Lehtonen et al., 2009b; Potti \& Canal, 2011) and are likely honest signals of male quality (e.g., Potti \& Montalvo, 1991b; Slagsvold \& Lifjeld, 1992; Sætre et al., 1994; Gustafsson et al., 1995; Sheldon et al., 1997; Sirkiä \& Laaksonen, 2009). Further, all favoured traits were uncorrelated, suggesting that each one may signal a different aspect of quality, as in zebra finches (Taeniopygia guttata; Birkhead et al., 1998) or great tits (Parus major; Rivera Gutierrez et al., 2010; see also references in Candolin, 2003). In pied flycatchers, a large size, as scored by tarsus length, may be beneficial in intrasexual competition (Sirkiä \& Laaksonen, 2009) and is indirectly related to fledgling survival (through its relationship with body condition; Alatalo et al., 1990). Plumage colour is also related to individual quality in this species, as darker males are the first to establish breeding territories on the arrival from spring migration (Lundberg \& Alatalo, 1992), have larger song repertories (Lampe \& Espmark, 1994) and feed their chicks at higher rates than browner males (Sætre et al., 1995). The white forehead patch functions as a badge of status in black-and-white European flycatchers (Qvarnström, 1997; Sanz, 2001), with large-ornamented males enjoying competitive advantages both in male conflicts over nest sites and in acquiring females more quickly (Potti \& Montalvo, 1991b; Pärt \& Qvarnström, 1997). Moreover, in 
collared flycatchers size of the forehead patch is related to male lifetime reproductive success and the likelihood of becoming polygynous and losing paternity (Gustafsson et al., 1995; Sheldon et al., 1997).

Discrepancies across same species' populations in traits involved in extrapair paternity contexts are not rare in the literature (e.g., great tit; Strohbach et al., 1998; Kawano et al., 2009; blue tits Cyanistes caeruleus; Kempenaers et al., 1992, 1997; Charmantier et al., 2004; red-winged blackbirds Agelaius phoeniceus; Weatherhead \& Boag, 1995; Wesneat, 2006; reviewed in Akçay \& Roughgarden, 2007) and the pied flycatcher is not an exception as no trait except age has been found to be associated to success in EPP in most previous studies of the species (Rätti et al., 1995; Slagsvold et al., 2001; Moreno et al., 2010; but see Lehtonen et al., 2009a). Differences among populations may be due to past selection on those traits being nowadays weak or non-existent in some of them (Dale et al., 1999), which would influence what traits are currently being selected in (extra- and within-pair) mating behaviour (Endler \& Houde, 1995; Westneat et al., 2006; Dunn et al., 2008). Additionally, breeding synchrony and density may determine how male and female behaviour interact to give the different EPP rates and patterns seen across populations (Griffith et al., 2002; Westneat \& Stewart, 2003). Many studies concerning EPP, especially the early ones, may have failed in the detection of phenotypic traits involved in EPP contexts due to low sample sizes (Lubjuhn et al., 2007; see also appendix 2 in Griffith et al., 2002).

Extra-pair paternity may strengthen sexual selection when paternity gains are related to particular male traits and are not counteracted by similar losses of WPY (Webster et al., 1995) as, in this case, there will be little or no influence of EPP on the total male reproductive output (Freeman-Galllant et al., 2005). In fact, some studies suggest that EPP does not boost male fitness in monogamous species as much (e.g., Dunn et al., 2001; Webster et al., 2001; Whittingham \& Dunn, 2005) as initially assumed (Birkhead \& Møller, 1992; Møller \& Ninni, 1998). In our population, siring additional young increased reproductive success because gaining EPP did not imply concurrent loss of paternity, i.e., most males gaining paternity did not lose it in their own nests. Comparisons among males revealed that cuckolders sired 2 more young, on average, than males engaging in faithful matings (and 5 more young than cuckolded males). Our results regarding male fitness are similar to those recently found in mountain bluebirds (Sialia currucoides; Balenger et al., 2008) but differ from those in species, as the yellow warbler (Dendroica petechia), in which EPP may dramatically increase male fitness 
(Yezerinac et al., 1995), likely because most males engaged only in one EPP mating and pure EPY broods were infrequent. Interestingly, from a point of view of loss of paternity, the rarity of pure EPY broods entailed that success in attaining EPP compensated for the risks of simultaneous cuckoldry because, when that happened, the males' reproductive output was similar to that of males only engaged in faithful matings.

It is tempting to suggest, on the basis of our results, that females may be able to assess and compare, based on the males' phenotypes, the quality of their social and EPP mates (Jennions \& Petrie, 2000). As a consequence, females paired with high quality males may be less prone to promiscuity whereas those paired with low quality males may actively solicit extra-pair copulations in order to gain some kind of benefit (Kempenaers et al., 1992). An alternative explanation is that cuckolder, high quality males may either invest more in pursuing extra-pair copulations, or be more capable of attaining these (Alatalo et al., 1987; Weatherhead \& Boag, 1995; Dunn \& Cockburn, 1999; Bitton, 2007) or in enforcing copulations from reluctant females (Arnqvist \& Kirkpatrick, 2005). Most likely, however, our results arise from the interactions of females with their social and EPP mates being contingent on a set of ecological factors constraining EPP opportunities (Westneat \& Stewart, 2003; van Dongen \& Mulder 2009). That cuckolder males are not completely safe from cuckoldry may be explained by the fact that females paired with high quality males may have male neighbours of even higher quality (Akçay \& Roughgarden, 2007).

To conclude, we have identified some predictors of male success in extrapair paternity and shown the importance of this behaviour in boosting male reproductive fitness. These findings suggest that EPP may be contributing to the evolution of the selected male traits in this population. Our results contrast with those of previous work in pied flycatchers and highlight the divergence on traits related to EPP success among populations. It remains a task for the future to experimentally ascertain to what extent these results are a consequence of female preference for particular male characters or due to a higher ability of large males displaying more elaborate traits to secure genetic polygamy.

\section{Acknowledgements}

We thank Inés Valencia for her dedicated assistance in the field and Inés Sanchez and Ester Ferrero for advice in the lab. We also thank László Garamszegi for statistical advice, Pedro 
Cordero for useful comments on a first draft and the anonymous reviewers for enlightening comments. Consejería de Medio Ambiente, Comunidad de Madrid and Delegación de Medio Ambiente, Junta de Castilla-La Mancha gave us working permissions. This work was supported by projects PAC05-006-2 (to J.A.D.) and CGL2006-07481/BOS (to J.C. Senar). D.C. was supported by a grant from the Ministerio de Educación y Ciencia (I3P-BDP2005).

\section{References}

Akçay, E. \& Roughgarden, J. (2007). Extra-pair paternity in birds: review of the genetic benefits. — Evol. Ecol. Res. 9: 855-868.

Alatalo, R.V., Gottlander, K. \& Lundberg, A. (1987). Extra-pair copulations and mateguarding in the polyterritorial pied flycatcher (Ficedula hypoleuca). - Behaviour 101: 139-155.

Alatalo, R.V., Gustafsson, L. \& Lundberg, A. (1990). Phenotypic selection on heritable size traits: environmental variance and genetic response. - Am. Nat. 135: 464-471.

Alatalo, R.V. \& Lundberg, A. (1986). Heritability and selection on tarsus length in the pied flycatcher (Ficedula hypoleuca). — Evolution 40: 574-583.

Albrecht, T., Vinkler, M., Schnitzer, J., Poláková, R., Munclinger, P. \& Bryja, J. (2009). Extrapair fertilizations contribute to selection on secondary male ornamentation in a socially monogamous passerine. - J. Evol. Biol. 22: 2020-2030.

Andersson, M. (1994). Sexual selection. - Princeton University Press, Princeton, NJ.

Arnqvist, G. \& Kirkpatrick, M. (2005). The evolution of infidelity in socially monogamous passerines: the strength of direct and indirect selection on extrapair copulation behavior in females. - Am. Nat. 165: S26-S37.

Balenger, S., Johnson, L.S. \& Masters, B. (2009). Sexual selection in a socially monogamous bird: male color predicts paternity success in the mountain bluebird, Sialia currucoides.

- Behav. Ecol. Sociobiol. 63: 403-411.

Birkhead, T.R., Fletcher, F. \& Pellatt, E.J. (1998). Sexual selection in the zebra finch Taeniopygia guttata: condition, sex traits and immune capacity. - Behav. Ecol. Sociobiol. 44: 179-191.

Birkhead, T.R. \& Møller, A.P. (1992). Sperm competition in birds: evolutionary causes and consequences. - Academic Press, London.

Bitton, P.-P., O’Brien, E.L. \& Dawson, R.D. (2007). Plumage brightness and age predict male extra-pair fertilization success in tree swallows Tachycineta bicolor. - Anim. Behav. 74: $1777-1784$.

Bouwman, K.M., Van Dijk, R.E., Wijmenga, J.J. \& Komdeur, J. (2007). Older male reed buntings are more successful at gaining extrapair fertilizations. - Anim. Behav. 73: 15-27.

Brün, J., Winkel, W., Epplen, J.T. \& Lubjuhn, T. (1996). Parentage analyses in the pied flycatcher (Ficedula hypoleuca) at the western boundary of its central European range. - J. Ornithol. 137: 435-446.

Canal, D., Dávila, J.A., de Nova, P.J.C., Ferrero, E. \& Potti, J. (2009). Polymorphic microsatellite markers isolated from a southern European population of pied flycatcher (Ficedula hypoleuca iberiae). — Mol. Ecol. Res. 9: 1375-1379.

Candolin, U. (2003). The use of multiple cues in mate choice. - Biol. Rev. 78: 575-595. 
Candolin, U. \& Voigt, H.R. (2001). Correlation between male size and territory quality: consequence of male competition or predation risk? - Oikos 95: 225-230.

Charmantier, A., Blondel, J., Perret, P. \& Lambrechts, M.M. (2004). Do extra-pair paternities provide genetic benefits for female blue tits Parus caeruleus? - J. Avian Biol. 35: 524-532.

Cohas, A. \& Allainé, D. (2009). Social structure influences extra-pair paternity in socially monogamous mammals. — Biol. Lett. 5: 313-316.

Cordero, P.J., Wetton, J.H. \& Parkin, D.T. (1999). Extra-pair paternity and male badge size in the house sparrow. - J. Avian Biol. 30: 97-102.

Dale, S. \& Slagsvold, T. (1996). Mate choice on multiple cues, decision rules and sampling strategies in female pied flycatchers. - Behaviour 133: 903-944.

Dale, S., Slagsvold, T., Lampe, H.M. \& Sætre, G.-P. (1999). Population divergence in sexual ornaments: the white forehead patch of Norwegian pied flycatchers is small and unsexy. - Evolution 53: 1235-1246.

Dixon, A., Ross, D., O’Malley, S.L.C. \& Burke, T. (1994). Paternal investment inversely related to degree of extra-pair paternity in the reed bunting. - Nature 371: 698-700.

Dunlop, W.P., Cortina, J.M., Vaslow, J.B. \& Burke, M.J. (1996). Meta-analysis of experiments with matched groups or repeated measures designs. - Psychol. Methods 1: 170-177.

Dunn, P.O. \& Cockburn, A. (1999). Extrapair mate choice and honest signaling in cooperatively breeding superb fairy-wrens. - Evolution 53: 938-946.

Dunn, P.O., Whittingham, L.A., Freeman-Gallant, C. \& DeCoste, J. (2008). Geographic variation in the function of ornaments in the common yellowthroat. - J. Avian Biol. 39: 66-72.

Dunn, P.O., Whittingham, L.A. \& Pitcher, T.E. (2001). Mating systems, sperm competition, and the evolution of sexual dimorphism in birds. - Evolution 53: 161-175.

Ellegren, H. (1992). Polymerase-chain-reaction (PCR). Analysis of microsatellites - a new approach to studies of genetic relationships in birds. - Auk 109: 886-895.

Ellegren, H., Gustafsson, L. \& Sheldon, B.C. (1996). Sex ratio adjustment in relation to paternal attractiveness in a wild bird population. - Proc. Natl. Acad. Sci. USA 93: 11723-11728.

Endler, J.A. (1977). Geographic variation, speciation and clines. — Princeton University Press, Princeton, NJ.

Endler, J.A. \& Houde, A.E. (1995). Geographic variation in female preferences for male traits in Poecilia reticulate. - Evolution 49: 456-468.

Freeberg, T.M., Duncan, S.D., Kast, T.L. \& Enstrom, D.A. (1999). Cultural influences on female mate choice: an experimental test in cowbirds, Molothrus ater. - Anim. Behav. 57: 421-426.

Freeman-Gallant, C.R., Wheelwright, N.T., Meiklejohn, K.E., States, S.L. \& Sollecito S.V. (2005). Little effect of extrapair paternity on the opportunity for sexual selection in savannah sparrows (Passerculus sandwichensis). - Evolution 59: 422-430.

Garamszegi, L.Z. (2006). Comparing effect sizes across variables: generalization without the need for Bonferroni correction. - Behav. Ecol. 17: 682-687.

Gelter, H.P. \& Tegelström, M. (1992). High frequency of extra-pair paternity in Swedish pied flycatchers revealed by allozyme electrophoresis and DNA fingerprinting. - Behav. Ecol. Sociobiol. 31: 1-7.

Griffith, S.C. (2007). The evolution of infidelity in socially monogamous passerines: neglected components of direct and indirect selection. — Am. Nat. 169: 274-281. 
Griffith, S.C., Owens, I.P.F. \& Thuman, A.K. (2002). Extra-pair paternity in birds: a review of interspecific variation and adaptive function. - Mol. Ecol. 11: 2195-2212.

Gustafsson, L., Qvarnström, A. \& Sheldon, B.C. (1995). Trade-offs between life-history traits and a secondary sexual character in male collared flycatchers. - Nature 375: 311-313.

Haavie, J., Sætre, G.-P. \& Moum, T. (2000). Discrepancies in population differentiation at microsatellites, mitochondrial DNA and plumage colour in the pied flycatcher inferring evolutionary processes. - Mol. Ecol. 9: 1137-1148.

Hutchinson, J.M.C. \& Griffith, S.C. (2008). Extra-pair paternity in the Skylark Alauda arvensis. - Ibis 150: 90-97.

Iwasa, Y. \& Pomiankowski, A. (1994). The evolution of mate preferences for multiple sexual ornaments. - Evolution 48: 853-867.

Jawor, J.M., Gray, N., Beall, S.M. \& Breitwisch, R. (2004). Multiple ornaments correlate with aspects of condition and behaviour in female Northern Cardinals Cardinalis cardinalis. — Anim. Behav. 67: 875-882.

Jennions, M.D. \& Petrie, M. (2000). Why do females mate multiply? A review of the genetic benefits. - Biol. Rev. 75: 21-64.

Johnson, L.S., Hicks, B.G. \& Masters, B.S. (2002). Increased cuckoldry as a cost of breeding late for males in the house wren (Troglodytes aedon). - Behav. Ecol. 13: 670-675.

Kawano, K.M., Yamaguchi, N., Kasuya, E. \& Yahara, T. (2009). Extra-pair mate choice in the female great tit Parus major: good males or compatible males. — Ethology 27: 349-359.

Kempenaers, B., Everding, S., Bishop, C., Boag, P. \& Robertson, R.J. (2001). Extra-pair paternity and the reproductive role of male floaters in the tree swallow (Tachycineta bicolor). - Behav. Ecol. Sociobiol. 49: 251-259.

Kempenaers, B., Geert, R. \& Dhondt, A. (1997). Extrapair paternity in the blue tit (Parus caeruleus): female choice male characteristics and offspring quality. - Behav. Ecol. 8: 481-492.

Kempenaers, B., Verheyen, G.R. \& Van den Broek, M. (1992). Extra pair paternity results from female preference for high quality males in the blue tit. - Nature 357: 494-496.

Kokko, H., Gunnarsson, T.G., Morrell, L.J. \& Gill, J.A. (2006). Why do female migratory birds arrive later than males? - J. Anim. Ecol. 75: 1293-1303.

Kokko, H. \& Lindström, J. (1996). Evolution of female preference for old mates. - Proc. Roy. Soc. Lond. B: Biol. 263: 1533-1538.

Lampe, H.M. \& Espmark, Y.O. (1994). Song structure reflects male quality in pied flycatchers Ficedula hypoleuca. — Anim. Behav. 47: 869-876.

Lande, R. (1981). Models of speciation by sexual selection on polygenic traits. — Proc. Natl. Acad. Sci. USA 78: 3721-3725.

Leder, E.H., Karaiskou, N. \& Primmer, C.R. (2008). Seventy new microsatellites for the pied flycatcher, Ficedula hypoleuca and amplification in other passerine birds. - Mol. Ecol. Res. 8: 874-880.

Lehtonen, P.K., Laaksonen, T. et al. (2009b). Geographic patterns of genetic differentiation and plumage colour variation are different in the pied flycatcher (Ficedula hypoleuca).

- Mol. Ecol. 18: 4463-4476.

Lehtonen, P.K., Primmer, C.R. \& Laaksonen, T. (2009a). Different traits affect gain of extrapair paternity and loss of paternity in the pied flycatcher Ficedula hypoleuca. - Anim. Behav. 77: 1103-1110. 
Liebgold, E.B., Cabe, P.R., Jaeger, R.G. \& Leberg, P.L. (2006). Multiple paternity in a salamander with socially monogamous behaviour. - Mol. Ecol. 15: 4153-4160.

Lifjeld, J.T., Slagsvold, T., Dale, S. \& Ellegren, H. (1997). A sexually selected paradox in the Pied Flycatcher: attractive males are cuckolded. - Auk 114: 112-115.

Lifjeld, J.T., Slagsvold, T. \& Lampe, H.M. (1991). Low frequency of extrapair paternity in pied flycatcher revealed by DNA fingerprinting. - Behav. Ecol. Sociobiol. 29: 95-101.

Lubjuhn, T., Gerken, T., Brun, J. \& Schmoll, T. (2007). Yearling male great tits, Parus major, suffer more strongly from cuckoldry than older males. - Zoology 110: 387-397.

Lundberg, A. \& Alatalo, R.V. (1992). The pied flycatcher. - Poyser, London.

Marshall, T.C., Slate, J., Kruuk, L.E.B. \& Pemberton, J.M. (1998). Statistical confidence for likelihood-based paternity in natural populations. - Mol. Ecol. 7: 639-655.

Mays, H.L., Albrecht, T., Liu, M. \& Hill, G.E. (2008). Female choice for genetic complementarity in birds: a review. - Genetica 134: 147-158.

Møller, A.P., Brohede, J., Cuervo, J.J., de Lope, F. \& Primmer, C. (2003). Extrapair paternity in relation to sexual ornamentation, arrival date, and condition in a migratory bird. Behav. Ecol. 14: 707-712.

Møller, A.P. \& Ninni, P. (1998). Sperm competition and sexual selection: a meta-analysis of paternity studies in birds. - Behav. Ecol. Sociobiol. 43: 345-358.

Møller, A.P. \& Pomiankowski, A. (1993). Why have birds got multiple sexual ornaments? Behav. Ecol. Sociobiol. 32: 167-176.

Moreno, J., Martínez, J.G., Morales, J., Lobato, E., Merino, S., Tomás, G., Vásquez, R.A., Möstl, E. \& Osorno, J.L. (2010). Paternity loss in relation to male age territorial behaviour and stress in the Pied Flycatcher. - Ethology 116: 76-84.

Nakagawa, S. (2004). A farewell to Bonferroni: the problems of low statistical power and publication bias. - Behav. Ecol. 15: 1044-1045.

Neto, J.M., Hansson, B. \& Hasselquist, D. (2010). Low frequency of extra-pair paternity in Savi’s Warblers (Locustella luscinioides). - Behaviour 147: 1413-1429.

Pärt, T. \& Qvarnström, A. (1997). Badge size in collared flycatchers predicts outcome of male competition over territories. - Anim. Behav. 54: 893-899.

Pomiankowski, A. \& Iwasa, Y. (1993). Evolution of multiple sexual preferences by Fisher's runaway process of sexual selection. — Proc. R. Soc. Lond. B: Biol. 253: 173-181.

Potti, J., Blanco, G., Lemus, J.Á. \& Canal, D. (2007). Infectious offspring: how birds acquire and transmit an avian polyomavirus in the wild. - PLoS ONE 2, e1276 (doi:101371/journalpone0001276).

Potti, J. \& Canal, D. (2011). Heritability and genetic correlation between the sexes in a songbird sexual ornament. — Heredity 106: in press (doi:10.1038/hdy.2010.142).

Potti, J. \& Merino, S. (1994). Heritability estimates and maternal effects on tarsus length in Pied Flycatchers Ficedula hypoleuca. - Oecologia 100: 331-338.

Potti, J. \& Montalvo, S. (1991a). Return rate age at first breeding and natal dispersal of Pied Flycatchers Ficedula hypoleuca in central Spain. - Ardea 79: 419-428.

Potti, J. \& Montalvo, S. (1991b). Male arrival and female mate choice in Pied Flycatchers (Ficedula hypoleuca) in central Spain. - Ornis. Scand. 22: 45-54.

Potti, J. \& Montalvo, S. (1991c). Male colour variation in Spanish Pied Flycatchers (Ficedula hypoleuca). - Ibis 133: 293-299.

Primmer, G., Anders, M. \& Ellegren, H. (1996). New microsatellites from the pied flycatcher Ficedula hypoleuca and the swallow Hirundo rustica genomes. - Hereditas 124: 281283. 
Qvarnström, A. (1997). Experimentally increased badge size increases male competition and reduces male parental care in the collared flycatcher. - Proc. Roy. Soc. Lond. B: Biol. 264: 1225-1231.

Qvarnström, A. (1999). Genotype-by-environment interactions in the determination of the size of a secondary sexual character in the Collared Flycatcher (Ficedula albicollis). Evolution 53: 1564-1572.

Qvarnström, A., Rice, A.M. \& Ellegren, H. (2010). Speciation in Ficedula flycatchers. Phil. Trans. Roy. Soc. B 365: 1841-1852.

Rätti, O., Hovi, H., Lundberg, A., Tegelström, H. \& Alatalo, R.V. (1995). Extra-pair paternity and male characteristics in the pied flycatcher. - Behav. Ecol. Sociobiol. 37: 419-425.

Rätti, O., Lundberg, A., Tegelström, H. \& Alatalo, R.V. (2001). No evidence for effects of breeding density and male removal on extrapair paternity in the pied flycatcher. - Auk 118: 147-155.

Rivera-Gutierrez, H.F., Pinxten, R. \& Eens, M. (2010). Multiple signals for multiple messages: great tit, Parus major, song signals age and survival. — Anim. Behav. 80: 451459.

Sanz, J.J. (2001). Experimentally reduced male attractiveness increases parental care in the pied flycatcher Ficedula hypoleuca. - Behav. Ecol. 12: 171-176.

SAS Institute (2004). SAS/STAT 9.1. User's guide. - SAS Institute, Cary, NC.

Sætre, G.-P., Dale, S. \& Slagsvold, T. (1994). Female pied flycatchers prefer brightly coloured males. - Anim. Behav. 48: 1407-1416.

Sætre, G.-P., Fossnes, T. \& Slagsvold, T. (1995). Food provisioning in the pied flycatcher: do females gain from choosing bright-coloured males? - J. Anim. Ecol. 64: 21-30.

Schluter, D. \& Price, T. (1993). Honesty, perception and population divergence in sexually selected traits. — Proc. Roy. Soc. Lond. B: Biol. 253: 117-122.

Sefc, K.M., Mattersdorfer, K., Sturmbauer, C. \& Koblmüller, S. (2008). High frequency of multiple paternity in broods of a socially monogamous cichlid fish with biparental brood care. - Mol. Ecol. 17: 2531-2543.

Sheldon, B.C., Merilä, J., Qvarnström, A., Gustafsson, L. \& Ellegren, H. (1997). Paternal genetic contribution to offspring condition predicted by size of male secondary sexual character. — Proc. Roy. Soc. Lond. B: Biol. 264: 297-302.

Simmons, L.W. (2005). The evolution of polyandry: sperm competition, sperm selection, and offspring viability. - Annu. Rev. Ecol. Evol. Syst. 36: 125-146.

Sirkïa, M.P. \& Laaksonen, T. (2009). Distinguishing between male and territory quality: females choose multiple traits in the pied flycatcher. - Anim. Behav. 78: 1051-1060.

Slagsvold, T., Johnsen, A., Lampe, H.M. \& Lifjeld, J.T. (2001). Do female pied flycatchers seek extrapair copulations with familiar males? A test of the incomplete knowledge hypothesis. - Behav. Ecol. 12: 412-418.

Slagsvold, T. \& Lifjeld, J.T. (1992). Plumage color is a condition-dependent sexual trait in male pied flycatchers. - Evolution 46: 825-828.

Strohbach, S., Curio, E., Bathen, A., Epplen, J.T. \& Lubjuhn, T. (1998). Extra-pair paternity in the great tit (Parus major): a test of the 'good genes' hypothesis. - Behav. Ecol. 9: 388-396.

Svensson, L. (1992). Identification guide to European passerines. - Naturhistoriska Riksmuseet, Stockholm.

Török, J., Hegyi, G. \& Garamszegi, L.Z. (2003). Depigmented wing patch size is a conditiondependent indicator of viability in male collared flycatchers. — Behav. Ecol. 14: 382388. 
Van Dongen, W.F.D. \& Mulder, R.A. (2009). Multiple ornamentation, female breeding synchrony, and extra-pair mating success of golden whistlers (Pachycephala pectoralis). — J. Ornithol. 150: 607-620.

Van Doorn, G.S. \& Weissing, F.J. (2004). The evolution of female preference for multiple indicators of quality. - Am. Nat. 164: 173-186.

Weatherhead, P.J. \& Boag, P.T. (1995). Pair and extra-pair mating success relative to male quality in red-winged blackbirds. - Behav. Ecol. Sociobiol. 37: 81-91.

Webster, M.S., Chuang-Dobbs, H.C. \& Holmes, R.T. (2001). Microsatellite identification of extra-pair sires in a socially monogamous warbler. - Behav. Ecol. 12: 439-446.

Webster, M.S., Pruett-Jones, S., Westneat, D.F. \& Arnold, S.J. (1995). Measuring the effects of pairing success extra-pair copulations and mate quality on the opportunity for sexual selection. - Evolution 49: 1147-1157.

Westneat, D.F. (2006). No evidence of current sexual selection on sexually dimorphic traits in a bird with high variance in mating success. — Am. Nat. 167: E171-E189.

Westneat, D.F. \& Stewart, I.R.K. (2003). Extra-pair paternity in birds: causes, correlates, and conflict. - Annu. Rev. Ecol. Evol. Syst. 34: 365-396.

Wetton, J.H., Burke, T., Parkin, D.T. \& Cairns, E. (1995). Single-locus DNA fingerprinting reveals that male reproductive success increases with age through extra-pair paternity in the house sparrow (Passer domesticus). — Proc. Roy. Soc. Lond. B Biol. 260: 91-98.

Whittingham, L.A. \& Dunn, P.O. (2005). Effects of extra-pair and within-pair reproductive success on the opportunity for selection in birds. - Behav. Ecol. 16: 138-144.

Yezerinac, S.M. \& Weatherhead, P.J. (1997). Extra-pair mating, male plumage coloration and sexual selection in yellow warblers (Dendroica petechia). — Proc. Roy. Soc. Lond. B Biol. 264: 527-532.

Yezerinac, S.M., Weatherhead, P.J. \& Boag, P.T. (1995). Extra-pair paternity and the opportunity for sexual selection in a socially monogamous bird (Dendroica petechia). - Behav. Ecol. Sociobiol. 37: 179-188.

Zuk, M., Ligon, J.D. \& Thornhill, R. (1992). Effects of experimental manipulation of male secondary sex characters on female mate preference in red jungle fowl. - Anim. Behav. 44: 999-1006. 